\title{
Study of Railway Passenger Transport in the European Union
}

\author{
Svetla STOILOVA
}

\begin{abstract}
This paper examine the development of railway passenger transport in the European Union countries by using criteria related to the transportation process and the level of economic development of the countries. The study proposes a methodology based on the combination of multicriteria methods. In the first step we determine the indicators to be used in evaluating railway passenger development. As main criteria of the assessment we have chosen social and economic factors, infrastructure factors, factors associated with travel and technological factors. In the second step, using the Fuzzy AHP method, the weights of the criteria and sub-criteria have been calculated. In the third step, we have rated the studied countries by means of the PROMETHEE method. The results show that the factors associated with travel and technological factors have great importance in the ranking of the countries and that, when all factors are taken into account, the countries with the most highly developed railway passenger transport are Germany, Britain and France. The results of the method in the fourth step were compared by applying Cluster analysis. The railway passenger transport in European Union countries have been classified into 5 groups.
\end{abstract}

Keywords: classification; cluster analysis; FAHP; PROMETHEE; railway transport

\section{INTRODUCTION}

The study of the development of railways in different countries of the European Union is essential for transport policy at both national and international level. The development of passenger transport by rail is dependent on the economic, technical, technological, infrastructural and financial state of transport companies and the countries. The classification of rail passenger transport can be done in terms of one or more indicators, such as the number of passengers, passenger kilometres, trains kilometres, transport costs and other indicators. Each classification could serve different purposes and it is important for the development of railway passenger market as an attractive mode for transportation. The classification can contribute to strategic planning, regulation measures, guidance for investment and management, and the quality of transportation.

European railway transport development is monitored by different institutions such as the European Commission [1], the Independent Regulators' Group Rail [2] and the International Union of Railways [3]. Eurostat, the statistical office of the European Union, annually monitors various indicators of the development of railway transport. Its task is to provide the European Union with statistics at European level that enable comparisons between countries and regions.

The main aims of passenger transportation by rail are related to an increase in mobility, a decrease in the time it takes to travel and in transportation expenses, improvement of reliability and the number of transported passengers.

The purpose of the researches of the authors in the field of railway passenger development is to provide a measure of productivity in the railways, to justify a system of regulation for railway effectiveness, to analyse the factors for technical change in different companies. The mathematical models which have been applied are pricing models $[4,5]$, cost function $[6,7]$, distance functions [8,9], Malmquist productivity model [10], nonparametric frontier model, data envelopment analysis [1114], regression analysis by quadratic function and requirement function [15], analysis by operational and technical indicators [14].

Fraszczyk et al. [16] compared the statistical data on various passenger-related parameters of the railway system in a number of selected European countries and drew conclusions on the level of their performance.

Stamos et al. [17] conducted a clustering of reported measures in content structures (e.g. technical options, organizational and decision making structures, etc.) and assessed them in terms of their contribution to the enhancement of rail transport and focusing on South East Europe. Aifandopoulou et al. [18] investigated three fundamental transport modes for long-distance travel e Rail, Air and Road in Southeast Europe countries by modal split model.

Cantos et al. [10] studied the development of the efficiency of the 17 railway companies in Europe for the period between 1970 and 1995. The results indicate that railway companies in Spain (RENFE), Denmark (DSB), Belgium (SNCB), Finland (VR) and Austria (OBB) have made steady progress in comparison with the other railway companies. Cantos et al. [11] analysed the cost and revenue inefficiencies using data envelopment analysis model for 17 European railway companies. The authors determined that companies like the Swedish SJ, the Dutch NS, or the French SNCF showed very good performance in terms of both revenue and costs.

Loizides and Tsionas [6] developed a model, which aims to present the cost structure of 10 European railways over a period of time between 1970 and 1992 and, which is based on a general index of technical change. The rankings that are made by the authors are as follows: the most productive country is Germany, followed by the United Kingdom, Belgium, France, Italy, Netherlands, Greece, Denmark, Luxembourg and Portugal.

Justo and Suarez [15] presented a method of quantifying the efficiency level of European railway companies using a sample of 19 firms in the timeframe 1965 to 1998 . The research estimates the requirements function and the quadratic function. Both functions examine the following indicators: passengers, freight, kilometres of lines, the percentage of electrification and the percentage of kilometres of double line. The two 
functions have similar results. A ranking of the studied administrations is made using these factors. The research indicates that the most highly developed railway companies, in terms of both these factors, are those in Austria, Italy and Germany.

Kutlar et al. [11] studied 31 railway companies that provide passenger and freight services around the world. The data covers a period of 10 years from 2000 to 2009 . The study employs the data envelopment analysis method and Tobit regression to determine efficiency. The model uses six input variables: total annual costs of operation; average annual number of employees; total length of the main line in kilometres; the total number of traction vehicles; the total number of passenger cars; the total number of cargo cars, and five output ones such as the annual total revenues earned; total number of passengers transported, total number of passengers per kilometre; total cargo tonne transported; total cargo tonne per kilometre transported. The results show that SNCF from France, JR from Japan, CFL from Luxemburg, and FGC from Spain operate productively in a stable way.

Coelli and Parelman [8] examine the development of 17 European railway companies by analysing annual data for a six-year period from 1988 to 1993 and using the method of distance functions. The model is defined by staff level, the total of the distances each passenger travelled and by tonnes of freight, the total number of available freight wagons, transportation capacity, total revenues from passenger and freight transportation. The results indicate that the technical efficiency level of European railways ranges from 0.784 for Italy to 0.980 for the Netherlands.

Arrigo, Di Foggia [19, 20] examined the State aid for rail transport as a factor for railway development. The authors studied some European countries - Sweden, Britain, Italy, France, Germany and found out that the total revenue from the rail passenger market and public subsidies affects train kilometres which explain the development of the railway sector, as is the case in Italy.

$\mathrm{Yu}$ [14] did research on 40 global railway companies located in Asia (6), Western Europe (14), Eastern Europe (15), and Africa (5) for the year 2002 by using traditional data development analysis and network data development analysis. The results show that European countries such as Germany, Italy, Austria, Netherlands, Spain, Norway, and Switzerland are technically efficient.

Studies by Wetzel $[5,21]$ provide an analysis of the development of the factor of productivity using data from 31 railway companies in 22 European countries covering the years from 1990 to 2005. This indicator includes technical change, technical efficiency change, and scale effects. Cantos, Maudos [5] and Loizides, Tsionas [6] have also found out that improvements in rail technology are a key driver of productivity growth in the railway transport sector.

Vesković et al. [22] studied the level of evaluation railway passenger market liberalization in European countries using a model based on the theory of fuzzy sets. The criteria for evaluating the reform of the railway system are new regulations on railway, organizational form, management structure, market competition and privatization, the obligation of public transport, adaptation to changes, commercial business processes. The results determine three railway reform grades - high (10 countries), medium (5 countries) and low (4 countries).

The level of railway reforms in European Union countries is investigated also in [23].The experience in the major European countries, such as the United Kingdom, Germany, France, Italy, Spain and Sweden is given in [24].

The results of these studies can be summarised as follows: The classifications of railway market aim to deal with the following problems: transport problems related to improving the competitive position of the railway transport with regard to other modes of transportation; infrastructural problems - rehabilitation and development of the railway lines and stations; technical problems improving the technical level of rolling stocks; integrated problems concerned with the evolution of the productivity of the railways.

All these studies show that the most important factors defining the development of rail transport are: gross domestic product as a factor at the economic level, rail transport costs, which are influenced by productivity and efficiency improvements and the quality of rail services, operational efficiency and productivity of rolling stock.

The aim of this research is to study the development of rail passenger transport in the European Union countries by ranking the countries using different factors affecting their development. The establishment of a basic categorisation of national rail passenger systems for the purpose of the current analysis aims to inform about their level of development. The development of passenger rail transport affects tourism and business travel, economic development of both individual countries and the European Union. Thus, a general assessment of the degree of development of railway passenger transport can be made and a suitable method for this is Multi-criteria analysis.

The novel contribution of this paper is, on the one hand, that it outlines criteria for evaluating the development of railway passenger transportation and, on the other hand, that it produces a rating scale of the European Union countries.

The object of this research is passenger railway transport in 28 European Union countries. The methodology of the study includes: determining the indicators for examining the level of development of passenger railway transport; applying a combination of multicriteria methods in order to determine the rating of the studied countries, verification and sensitivity analysis of the results.

\section{METHODOLOGY}

The methodology includes several steps. In the first step, we specify the indicators used to assess railway passenger development. In the second step, using the Fuzzy Analytic Hierarchy Process (FAHP) method, we calculate the weights of the criteria and sub-criteria. In the third step, a ranking of the studied countries is made using the PROMETHEE method. In the fourth step the obtained results have been verified by applying the Cluster analysis method in order to classify the countries and to make a comparison of results. 


\subsection{Factors for Classification}

Railway passenger development is evaluated according to the four groups of main criteria: social and economic factors; infrastructure factors; factors associated with travel; technological factors. For each of these criteria the following sub-criteria have been determined: $F_{1}$ - Social and economic factors. These factors indicate the economic level of the countries. In this group the following sub-criteria have been studied:

$f_{11}$ - Gross domestic product (GDP), billion euro/year. This is an indicator of the economic development of a country, as well as a gauge of a country's standard of living.

$f_{12}$ - Gross domestic product per (PPP), euro/year. This indicator shows the level of the economic development of the countries and can be used to compare one country to another.

$f_{13}$ - Infrastructure charges, euro/train km. Railway undertakings pay infrastructure charges infrastructure managers for the use of rail infrastructure. The amount of infrastructure charges is an indicator of the economic level of railway transport and the maintenance of railway infrastructure.

$F_{2}$ - Infrastructure factors. These factors show the level of infrastructure development of railway lines. The subcriteria for this main group are:

$f_{21}$ - Length of the railway network, $\mathrm{km}$. This factor includes the length of all routes available for passenger traffic on the network.

$f_{22}$ - Coefficient of electrified railways. This indicator is calculated by dividing the length of electrified railways by the total length of railway network. It is a measure of the development of railway transport.

$f_{23}$ - Density of the railway network, $\mathrm{km} / \mathrm{km}^{2}$. This indicator presents the degree of development of railway transport. It shows how many kilometres of railway network there are in an area of one square kilometre.

$f_{24}$ - Availability of high-speed service. High-speed trains operate (almost always) in dedicated infrastructure and generally stop only in sizeable urban agglomerations. This indicator can take values 0 or $1 . f_{24}=1$ if the country has a high-speed railway service. $f_{24}=0$, otherwise.

$f_{25}$ - Number of junction stations. These are big stations transport centers, where passengers change trains and catch a train for another destination.

$F_{3}$ - Factors associated with travel. They present the level of usage of railway transport by passengers. In this main group the following sub-criteria are included:

$f_{31}$ - Number of passengers per year, thousands pass./year. Passengers travelling by long-distance conventional train services (e.g. Intercity), which often require seat reservation, medium-distance/regional train services and suburban/commuter train services.

$f_{32}$ - Number of passenger-kilometres per year, millions pass.km/year. This factor shows the availability of railway transport for passengers.

$f_{33}$ - Flexibility of travel. This indicator is calculated by dividing the number of passengers per year by the number of residents. It shows the degree of usage of railway passenger transport.

$f_{34}$ - Average distance travelled per resident, $\mathrm{km}$. This indicator is calculated by dividing the total passenger $\mathrm{km}$ per year by the number of residents. It shows the average distance travelled by railway passengers. $f_{35}$ - Intensity of day trips, pass. $/ \mathrm{km}$. This indicator shows the number of passengers per day for a kilometre of the railway network.

$F_{4}$ - Technological factors. These factors indicate the operational efficiency and the quality of rail passenger services. The sub-criteria that have been included in this group are:

$f_{41}$ - Number of passenger train kilometres per year, thousands pass.km/year. Train-kilometres refer to the distance actually covered by the train. It is an indication of how the rail network is being used in the national passenger market.

$f_{42}$ - Passenger network usage intensity. The passenger network usage intensity is calculated by dividing the passenger train $\mathrm{km}$ per day by the length of railway network in order to obtain the average number of trains per route kilometre per day. This shows the intensity with which the passenger market uses the rail network.

$f_{43}$ - Average number of passengers per train. This indicator is calculated by dividing the number of passenger kilometres by the number of train-kilometres. It presents the number of passengers by train and it is a measure of operational efficiency.

$f_{44}$ - Intensity of incident. This coefficient is calculated by dividing the passenger network usage intensity by the number of incidents for passenger trains per day. It is a measure of safety and security in railway transport.

\subsection{Fuzzy Analytic Hierarchy Process (FAHP)}

The study uses the FAHP methodology to determine the weights of the criteria and sub-criteria. This method has been designed for decision making and for selecting the best alternatives by integrating the concept of fuzzy set theory and hierarchical structure analysis. In this method the decision maker gives interval judgements as opposed to analytic hierarchy process (AHP) method where only estimation is given. This research uses Chang's extent approach to FAHP [25] for evaluation, which uses a pair-wise comparison scale based on triangular fuzzy numbers and the method of extent analysis. FAHP method is applied also in [26-29]. This method is relatively easier than other FAHPs and can be presented in several steps.

- Stage 1. Define the problem, the overall goal that has to be attained, criteria, sub-criteria, if necessary alternatives too. Define the hierarchy structure from the top level through the intermediate levels, which contain the criteria and sub-criteria, to the lowest level, which is related to the alternatives.

- Stage 2. Utilization of triangular fuzzy numbers for pairwise comparison using the FAHP scale presented in Tab. 1. The fuzzy evaluation matrix of the criteria is constructed through the pairwise comparison of different attributes relevant to the overall objective using the linguistic variables and triangular fuzzy numbers.

The elements of the triangular fuzzy comparison matrix $\tilde{\boldsymbol{A}}=\left(\tilde{a}_{i j}\right)_{n, n}$ for $i, j=1, \ldots, n ; i \neq j$ are calculated by the following equations:

$\tilde{a}_{i j}=\left(l_{i j}, m_{i j}, u_{i j}\right)=\frac{1}{\tilde{a}_{i j}}=\left(\frac{1}{u_{i j}}, \frac{1}{m_{i j}}, \frac{1}{l_{i j}}\right)$, 


Table 1 Triangular fuzzy scale
\begin{tabular}{|l|c|c|}
\hline Linguistic scale for importance & $\begin{array}{c}\text { Fuzzy } \\
\text { number }\end{array}$ & $\begin{array}{c}\text { Triangular fuzzy scale } \\
(l, m, u)\end{array}$ \\
\hline Just equal & 1 & $(1,1,1)$ \\
\hline Equally important & 1 & $(1,1,3)$ \\
\hline Weakly important & 3 & $(1,3,5)$ \\
\hline Essential or Strongly important & 5 & $(3,5,7)$ \\
\hline Very strongly important & 7 & $(5,7,9)$ \\
\hline Extremely preferred & 9 & $(7,9,9)$ \\
\hline Reciprocal value & & $(1 / u, 1 / m, 1 / l)$ \\
\hline
\end{tabular}

- Stage 3. In this stage the extent analysis is made using the extent analysis method in order to obtain priority weights by using synthetic extent values.

According to Chang [25], let $X=\left\{x_{1}, x_{2}, \ldots, x_{\mathrm{n}}\right\}$ be an object set, and $G=\left\{g_{1}, g_{2}, \ldots, g_{\mathrm{m}}\right\}$ be a goal set. Based on Chang's extent analysis, each object is taken and the extent analysis of each goal, $g_{i}$ is performed individually. The $m$ extent analysis values of each object can be obtained, with the following signs $M_{g_{i}}^{1}, M_{g_{i}}^{2}, \ldots, M_{g_{i}}^{m},(i$ $=1,2, \ldots, n, j=1,2, \ldots, m)$ where all the $M_{g_{i}}^{j}$, are triangular fuzzy numbers. They are the least possible value $(l)$, the most possible value $(m)$, and the largest possible value $(u)$.

The extent analysis can be expressed as follows, [25]:

- Step 1: Determining any matrix relative weight.

The value of the fuzzy synthetic extent with respect to the $i$ objects is defined as:

$$
S_{i}=\sum_{j=1}^{m} M_{g_{i}}^{j} \otimes \frac{1}{\left(\sum_{i=1}^{n} \sum_{j=1}^{m} M_{g_{i}}^{j}\right)},
$$

To obtain $\sum_{j=1}^{m} M_{g_{i}}^{j}$ (Fuzzy summation of row), fuzzy addition operation of $m$ extent analysis values for a particular matrix is performed as follows:

$M_{g_{i}}^{j}=\left(\sum_{j=1}^{m} l_{j}, \sum_{j=1}^{m} m_{j}, \sum_{j=1}^{m} u_{j}\right)$

To obtain $\frac{1}{\left(\sum_{i=1}^{n} \sum_{j=1}^{m} M_{g_{i}}^{j}\right)}$, fuzzy additional operation of $M_{g_{i}}^{j}$ is performed such as the summation of the contents of the columns.

$\sum_{i=1}^{n} \sum_{j=1}^{m} M_{g_{i}}^{j}=\left(\sum_{i=1}^{n} l_{i}, \sum_{i=1}^{n} m_{i}, \sum_{i=1}^{n} u_{i}\right)$

Then the inverse of the vector in Eq. (4) is computed as follows:

$\frac{1}{\sum_{i=1}^{n} \sum_{j=1}^{m} M_{g_{i}}^{j}}=\frac{1}{\sum_{i=1}^{n} u_{i}}, \frac{1}{\sum_{i=1}^{n} m_{i}}, \frac{1}{\sum_{i=1}^{n} l_{i}}$
- Step 2: Making a comparison between two triangular fuzzy numbers.

The degree of possibility of two triangular fuzzy numbers $M_{2}$ and $M_{1}$ is defined as:

$M_{2}\left(l_{2}, m_{2}, u_{2}\right) \geq M_{1}\left(l_{1}, m_{1}, u_{1}\right)$

It can be expressed as follows:

$$
\begin{aligned}
& V\left(M_{2} \geq M_{1}\right)=\operatorname{hgt}\left(M_{1} \cap M_{2}\right)=\mu_{M_{1}}\left(x_{d}\right), \\
& V\left(M_{2} \geq M_{1}\right)=1 \text { if } m_{2} \geq m_{1}, \\
& V\left(M_{2} \geq M_{1}\right)=0 \text { if } l_{1} \geq u_{2}, \\
& V\left(M_{2} \geq M_{1}\right)=\operatorname{hgt}\left(M_{1} \cap M_{2}\right)= \\
& =\frac{l_{1}-u_{2}}{\left(m_{2}-u_{2}\right)-\left(m_{1}-l_{1}\right)}=d,
\end{aligned}
$$

where: $d$ is the ordinate of the highest intersection point $D$ between $\mu_{\mathrm{M} 1}$ and $\mu_{\mathrm{M} 2}$.

To compare $M_{1}$ and $M_{2}$, both values of $V\left(M_{1} \geq M_{2}\right)$ and $V\left(M_{2} \geq M_{1}\right)$ are needed.

- Step 3: Determining the degree of possibility for a convex fuzzy number.

The degree of possibility for a convex fuzzy number to be greater than $k$ convex fuzzy numbers $M_{i}(i=1,2$, $\ldots, k)$ can be defined by:

$\left(M \geq M_{1}, M_{2}, \ldots, M_{k}\right)=\min V\left(M \geq M_{i}\right)$

Let us assume that the weight vector is given by:

$\hat{\boldsymbol{d}}\left(A_{i}\right)=\min V\left(S_{i} \geq S_{k}\right)$, for $k=1,2, \ldots, n, k \neq i$

where: $A_{i}$ are $n$ elements.

The weight vector is given by the following formula:

$\hat{\boldsymbol{W}}=\left(\hat{\boldsymbol{d}}\left(A_{1}\right), \hat{\boldsymbol{d}}\left(A_{2}\right), \ldots, \hat{\boldsymbol{d}}\left(A_{n}\right)\right)^{\mathrm{T}}$

- Step 4: Determination of the normalized weight vectors.

$W=\left(d\left(A_{1}\right), d\left(A_{2}\right), \ldots, d\left(A_{n}\right)\right)^{\mathrm{T}}$,

where: $W$ is a non-fuzzy number.

After this step the consistency ratio is calculated and its value is checked. The consistency ratio is found with the following formula:

$C R=\frac{C I}{R I} \leq 0,1$,

where: $C R$ is the consistency ratio; $C I$ is the consistency index; $R I$ is a random index. The random index is given by Saaty, [30]. 
If the $C R$ is much greater than 0,1 , the judgements are unreliable and the pair-wise comparison is valueless and it must be repeated.

The consistency index is:

$C I=\frac{\lambda_{\max }-n}{n-1}$

where $\lambda_{\max }$ is the maximum eigenvalue of the priority matrix, $n$ is the number of elements in the matrix.

$$
\begin{aligned}
& \lambda_{\max }=\sum_{i=1}^{n}\left[\left(\sum_{j=1}^{n} a_{i j}\right) \cdot W_{i}\right], \\
& W_{i}=\frac{1}{n} \cdot \sum_{j=1}^{n} \frac{a_{i j}}{\sum_{i=1}^{n} a_{i j}}
\end{aligned}
$$

As Eq. (16) and Eq. (17) are applied for the AHP method, a few transformations were made to determine $\lambda_{\max }$. The fuzzy matrix $\tilde{\boldsymbol{A}}$ can be expressed by three characteristic crisp matrices $\tilde{\boldsymbol{A}}=\left(A_{l}, A_{m}, A_{u}\right)$, where: $A_{l}=\left(a_{i j, l}\right)_{n, n} ; A_{m}=\left(a_{i j, m}\right)_{n, n} ; A_{u}=\left(a_{i j, u}\right)_{n, n}$. The

elements of the fuzzy matrix $\tilde{\boldsymbol{A}}$, fuzzy vector $\tilde{\boldsymbol{W}}$ and fuzzy eigenvalue are assumed to be triangular fizzy numbers, that may be denoted according to Eq. (1) as $\tilde{\boldsymbol{W}}=\left(W_{l}, W_{m}, W_{u}\right) ; \tilde{\lambda}=\left(\lambda_{l}, \lambda_{m}, \lambda_{u}\right)$. The fuzzy eigenvalue $\lambda_{l}, \lambda_{m}, \lambda_{u}$ corresponds to the maximum eigenvalue of the priority matrix $\lambda_{\max }$ by AHP method. They are determined separately using crisp matrices $A_{l}, A_{m}, A_{u}$ and weights $W_{l}$, $W_{m}, W_{u}$ by the Eq. (17) and Eq. (18).

In this research the eigenvalue is calculated for weighted mean method by [29]. The TFN can be defuzzied to a crisp number by weight mean method by the following equation:

$$
\tilde{A}_{\text {crisp }}=\lambda_{\max }=\frac{\lambda_{l}+4 \lambda_{m}+\lambda_{u}}{6} .
$$

\subsection{PROMETHEE Method for Ranking Railway Passenger Transport in the European Union countries}

After determining the weights of the criteria the PROMETHEE methodology is applied for ranking the investigated countries. The weights of the criteria determined by means of FAHP are used in the PROMETHEE method to estimate the alternatives. This method is based on a comparison of pair per pair of possible decisions along each criterion. Possible decisions are evaluated according to different criteria, which have to be maximized or minimized. The use of the PROMETHEE method requires two additional types of information for each criterion: a weight and a preference function. These functions are usually criterion, quasi criterion, criterion with linear preference, level criterion, criterion with linear preference and indifference area and Gaussian criterion. The explanation and mathematical calculation steps of the PROMETHEE method are summarised below [31]:
- Step 1: This step computes, for each pair of possible decisions and for each criterion, the value of the preference degree.

- Step 2: This step consists in aggregating the preference degrees of all criteria for each pair of possible decisions. For each pair of possible decisions, a global preference index has to be calculated.

- Step 3: This step is the first phase in determining the ranking of the criteria for each of the alternatives. The third step concerns the ranking of the possible decisions and includes the computing of the outranking flows. For each possible decision the positive outranking flow $\left(\varphi^{+}\right)$ and the negative outranking flow $\left(\varphi^{-}\right)$are computed.

- Step 4: This step is the second phase of determining the ranking of the criteria for each of the alternatives. The outranking flows are used to establish a complete ranking between the possible decisions. The net outranking flow $\varphi$ of a possible decision is computed as a difference between $\left(\varphi^{+}\right)$and $\left(\varphi^{-}\right)$. The highest value of the net outranking flow shows the best decision.

\section{VERIFICATION WITH CLUSTER ANALYSIS}

To verify the results, the Cluster analysis has been determined. It is a multi-measurable statistical analysis for a classification of units into groups by using different factors [32]. A method for hierarchical clustering has been used in the study. The main advantage of this method is that the determination of a unit into a specific cluster is definitive. In the paper the Hierarchical clustering is performed by the agglomerative method Between Groups. For the distance-type measures, the Euclidean distance [32] was chosen. The cluster analysis has been conducted by using the criteria specified in 2.1 .

The dispersion analysis could be used for an approximate evaluation of the clusterisation's results as well as for determining the roles of each variable used for clusters' establishment. The determination of the statistical importance of different factors is done by using the $F$ criterion (Fisher's criterion).

$F \geq F_{\mathrm{T}}$

where: $F$ is the empirical value of the criterion resulting from the dispersion analysis, $F_{\mathrm{T}}$ is the theoretical value when the level of risk $\alpha=0,05$ and the number of degrees of freedom,,$k_{1}=m-n ; k_{2}=n-1 ; m$ is the number of countries $-28, n$ is the number of examined factors -17 . On one hand, the Fisher criterion's evaluation determines which factors are significant for the study, on the other it does not dismiss those other factors which are used for clusterisation but does not satisfy Eq. (20).

\section{RESULTS AND DISCUSSION}

The described model has been used to assess passenger railway development in 28 European countries. To determine the values of the criteria and sub-criteria for the investigated countries a data base for a ten-year period from 2005 to 2014 has been created. The average value for each of indices that are shown in Tab. 2 has been applied in the research. The United Kingdom is also 
included in the study because it has been a member in the study period.

Several studies reported findings from AHP with different numbers of experts: 20 experts for 43 factors [28]; 38 experts for 25 factors [33]; 7 experts for 31 factors [34]. Increasing the number of experts generally leads to increased reliability of expertise. The number of experts may be reduced if you select specialists with higher competence.

In this research the number of experts is 18 professionals with experience in passenger railway transport more than 20 years (six academics and twelve railway passenger industry specialists). The experts were asked to perform pairwise comparisons of all factors.

The values of each of the triangular fuzzy numbers (the least possible value $l$, the most possible value $m$, and the largest possible value $u$ ) have been determined as average values obtained from the estimates made by the experts. The pairwise comparison of the main criteria presented in Tab. 3, Tab. 4, Tab. 5, Tab. 6 and Tab. 7 show the pairwise comparison of the sub-criteria. In the last columns of the tables are given the local and the global weights.

The local weights are the normalised weights that show the weight of each sub-criterion in the respective group of the main criterion. The global weights show the priority of all sub-criteria taking into account the weights of main criteria. Tab. 3 shows that factors associated with travel $\left(F_{3}\right)$ have higher priority than the other criteria $(0,32)$. From the main group of social and economic factors, the gross domestic product sub-criterion has the highest priority; with the infrastructure factors the highest priority is that of the length of the railway network available for passenger traffic.

Table 2 Values of sub-criteria

\begin{tabular}{|c|c|c|c|c|c|c|c|c|c|c|c|c|c|c|c|c|c|}
\hline Country & $f_{11}$ & $f_{12}$ & $f_{13}$ & $f_{21}$ & $f_{22}$ & $f_{23}$ & $f_{24}$ & $f_{25}$ & $f_{31}$ & $f_{32}$ & $f_{33}$ & $f_{34}$ & $f_{35}$ & $f_{41}$ & $f_{42}$ & $f_{43}$ & $f_{44}$ \\
\hline AT & 277 & 36512 & 3,64 & 5788 & 0,88 & 0,07 & yes & 35 & 237218 & 9312 & 29 & 1121 & 112 & 150831 & 71 & 62 & 0,0038 \\
\hline $\mathrm{BE}$ & 376 & 34975 & 5,39 & 3546 & 0,84 & 0,12 & yes & 16 & 202387 & 9568 & 19 & 800 & 156 & 94046 & 73 & 102 & 0,0021 \\
\hline BG & 35 & 4692 & 1,33 & 4155 & 0,69 & 0,04 & no & 18 & 30542 & 2139 & 4 & 285 & 20 & 30171 & 20 & 71 & 0,0085 \\
\hline $\mathrm{CH}$ & 419 & 54591 & 3,03 & 5057 & 1,00 & 0,12 & yes & 14 & 448101 & 17699 & 58 & 2305 & 243 & 210515 & 114 & 84 & 0,0016 \\
\hline $\mathrm{CZ}$ & 149 & 14442 & 1,33 & 9589 & 0,32 & 0,12 & yes & 20 & 174903 & 6825 & 17 & 659 & 50 & 154264 & 44 & 44 & 0,0099 \\
\hline DE & 2551 & 31183 & 4,99 & 39307 & 0,66 & 0,11 & yes & 135 & 2320353 & 82058 & 28 & 1003 & 162 & 978728 & 68 & 84 & 0,0238 \\
\hline DK & 242 & 44025 & 0,29 & 3167 & 0,20 & 0,07 & yes & 41 & 184185 & 6103 & 34 & 1110 & 159 & 76502 & 66 & 80 & 0,0010 \\
\hline $\mathrm{EE}$ & 15 & 11708 & 2,10 & 1140 & 0,11 & 0,03 & no & 7 & 4952 & 244 & 4 & 182 & 12 & 7600 & 18 & 32 & 0,0064 \\
\hline ES & 1050 & 23275 & 2,07 & 13393 & 0,61 & 0,03 & yes & 99 & 592752 & 22062 & 13 & 489 & 121 & 204653 & 42 & 108 & 0,0059 \\
\hline FI & 185 & 34808 & 0,72 & 5877 & 0,50 & 0,02 & yes & 42 & 66758 & 3772 & 13 & 709 & 31 & 50707 & 24 & 74 & 0,0055 \\
\hline FR & 1974 & 30825 & 4,50 & 30525 & 0,43 & 0,05 & yes & 171 & 1065601 & 84570 & 17 & 1321 & 96 & 495409 & 44 & 171 & 0,0100 \\
\hline GR & 221 & 19925 & 1,48 & 2722 & 0,05 & 0,02 & no & 34 & 12464 & 1518 & 1 & 137 & 13 & 16780 & 17 & 90 & 0,0067 \\
\hline HR & 45 & 10425 & 2,05 & 2723 & 0,36 & 0,03 & no & 16 & 50059 & 1396 & 12 & 325 & 50 & 25440 & 26 & 55 & 0,0063 \\
\hline $\mathrm{HU}$ & 99 & 9892 & 1,50 & 7718 & 0,37 & 0,08 & no & 34 & 145131 & 8039 & 14 & 802 & 52 & 102001 & 36 & 79 & 0,0402 \\
\hline IE & 167 & 38100 & 4,47 & 1894 & 0,06 & 0,03 & no & 21 & 39418 & 1736 & 9 & 397 & 57 & 16635 & 24 & 104 & 0,0003 \\
\hline IT & 1596 & 27167 & 2,74 & 16412 & 0,71 & 0,05 & yes & 114 & 796302 & 45707 & 14 & 778 & 133 & 363502 & 61 & 126 & 0,0062 \\
\hline LT & 310 & 9640 & 4,19 & 1770 & 0,07 & 0,03 & no & 6 & 4537 & 261 & 1 & 82 & 7 & 14528 & 22 & 18 & 0,0085 \\
\hline LU & 38 & 76700 & 1,66 & 530 & 0,49 & 0,20 & no & 3 & 16588 & 319 & 34 & 646 & 86 & 7519 & 39 & 42 & 0,0001 \\
\hline LV & 19 & 9033 & 5,00 & 2111 & 0,12 & 0,03 & no & 11 & 23340 & 826 & 11 & 383 & 30 & 18318 & 24 & 45 & 0,0053 \\
\hline NL & 615 & 37300 & 1,57 & 2871 & 0,74 & 0,07 & yes & 20 & 345460 & 15229 & 21 & 923 & 330 & 118319 & 113 & 129 & 0,0007 \\
\hline $\mathrm{NO}$ & 320 & 66775 & 0,60 & 4028 & 0,63 & 0,01 & yes & 40 & 58855 & 2987 & 12 & 623 & 40 & 43280 & 29 & 69 & 0,0020 \\
\hline PL & 336 & 8817 & 2,34 & 20179 & 0,59 & 0,06 & yes & 41 & 258429 & 18065 & 7 & 474 & 35 & 212262 & 29 & 85 & 0,0756 \\
\hline PT & 175 & 16642 & 1,38 & 2772 & 0,55 & 0,03 & yes & 31 & 148397 & 3959 & 14 & 377 & 147 & 38854 & 38 & 102 & 0,0047 \\
\hline $\mathrm{RO}$ & 124 & 5992 & 2,21 & 10855 & 0,37 & 0,05 & no & 76 & 76331 & 6409 & 4 & 309 & 19 & 91846 & 23 & 70 & 0,0321 \\
\hline SE & 359 & 38875 & 0,83 & 11070 & 0,71 & 0,03 & yes & 49 & 174285 & 10607 & 19 & 1147 & 43 & 137661 & 34 & 77 & 0,0055 \\
\hline SI & 32 & 15742 & 1,12 & 1224 & 0,41 & 0,06 & no & 9 & 15573 & 717 & 8 & 354 & 35 & 18705 & 42 & 38 & 0,0022 \\
\hline SK & 63 & 11650 & 1,81 & 3639 & 0,43 & 0,07 & no & 14 & 15573 & 2303 & 9 & 428 & 36 & 45742 & 34 & 50 & 0,0224 \\
\hline UK & 1815 & 29358 & 1,62 & 16035 & 0,33 & 0,06 & yes & 70 & 1311888 & 52902 & 21 & 856 & 224 & 507610 & 87 & 104 & 0,0027 \\
\hline
\end{tabular}

Table 3 Fuzzy evaluation pairwise comparison matrix of the main criteria

\begin{tabular}{|c|c|c|c|c|c|c|c|c|c|c|c|c|c|}
\hline & \multicolumn{4}{|c|}{$F_{1}$} & \multicolumn{3}{|c|}{$F_{2}$} & \multicolumn{3}{|c|}{$F_{3}$} & \multicolumn{2}{|c|}{$F_{4}$} \\
\hline & $l$ & $m$ & $u$ & $l$ & $m$ & $u$ & $l$ & $m$ & $u$ & $l$ & $m$ & $u$ & \\
\hline$F_{1}$ & 1 & 1 & 1 & 0,26 & 0,62 & 1 & 0,34 & 0,60 & 0,90 & 0,26 & 0,62 & 1 & 0,15 \\
\hline$F_{2}$ & 1 & 1,62 & 3,89 & 1 & 1 & 1 & 0,21 & 0,47 & 0,71 & 0,36 & 0,68 & 0,90 & 0,24 \\
\hline$F_{3}$ & 1,11 & 1,67 & 2,91 & 1,40 & 2,14 & 4,68 & 1 & 1 & 1 & 1 & 1,29 & 2,71 & 0,32 \\
\hline$F_{4}$ & 1 & 1,62 & 3,89 & 1,11 & 1,48 & 2,82 & 0,37 & 0,78 & 1 & 1 & 1 & 1 & 0,29 \\
\hline
\end{tabular}

Table 4 Fuzzy evaluation pair-wise comparison of the sub-criteria of main criterion $F_{1}$

\begin{tabular}{|c|c|c|c|c|c|c|c|c|c|c|c|}
\hline$F_{1}$ & \multicolumn{4}{|c|}{$f_{11}$} & \multicolumn{3}{|c|}{$f_{12}$} & \multicolumn{3}{|c|}{$f_{13}$} \\
\hline & $l$ & $m$ & $u$ & $l$ & $m$ & $u$ & $l$ & $m$ & $u$ & Local & Global \\
\hline$f_{11}$ & 1 & 1 & 1 & 1 & 1,57 & 3,29 & 1 & 2,14 & 4,14 & 0,43 & 0,07 \\
\hline$f_{12}$ & 0,30 & 0,64 & 1 & 1 & 1 & 1 & 1 & 1,29 & 3,29 & 0,33 & 0,05 \\
\hline$f_{13}$ & 0,24 & 0,47 & 1,00 & 0,30 & 0,78 & 1 & 1 & 1,00 & 1,00 & 0,22 & 0,03 \\
\hline
\end{tabular}

About factors associated with travel, the highest priority is the number of passengers per year and with technological factors the highest priority is the number of passenger train kilometres per year. Taking into account all sub-factors it can be seen that the greatest impact has the factor about the number of passenger train kilometres per year. 
The value of $C R<0,1$, for both the main criteria and the sub-criteria (all main criteria 0,09; all sub criteria of $F_{1} 0,09$; all sub criteria of $F_{21} 0,09$; all sub criteria of $F_{3} 0,08$; all sub criteria of $F_{4} 0,08$ ). It can be said that there is sufficient consistency in the estimates of experts.
The given results of the weights by the FAHP method have been applied for studying the rating of passenger railway transport of the European Union countries using PROMETHEE method. The research was done with Visual PROMETHEE Software.

Table 5 Fuzzy evaluation pair-wise comparison of the sub-criteria of main criterion $F_{2}$

\begin{tabular}{|c|c|c|c|c|c|c|c|c|c|c|c|c|c|c|c|c|c|}
\hline$F_{2}$ & \multicolumn{3}{|c|}{$f_{21}$} & \multicolumn{3}{|c|}{$f_{22}$} & \multicolumn{3}{|c|}{$f_{23}$} & \multicolumn{3}{|c|}{$f_{24}$} & \multicolumn{3}{|c|}{$f_{25}$} & \multicolumn{2}{|c|}{ Weight } \\
\hline & $l$ & $m$ & $u$ & $l$ & $m$ & $u$ & $l$ & $m$ & $u$ & $l$ & $m$ & $u$ & $l$ & $m$ & $u$ & Local & Global \\
\hline$f_{21}$ & 1 & 1 & 1 & 1 & 2,43 & 4,43 & 1,57 & 3,29 & 5,29 & 1,29 & 2,43 & 4,14 & 1 & 1,86 & 3,29 & 0,33 & 0,08 \\
\hline$f_{22}$ & 0,23 & 0,41 & 1 & 1 & 1 & 1 & 1 & 1 & 2,14 & 0,25 & 0,6 & 0,90 & 1 & 1 & 2,14 & 0,16 & 0,04 \\
\hline$f_{23}$ & 0,19 & 0,30 & 0,64 & 0,47 & 1 & 1 & 1 & 1 & 1 & 1 & 1 & 2,43 & 1 & 1,29 & 2,71 & 0,18 & 0,04 \\
\hline$f_{24}$ & 0,24 & 0,41 & 0,78 & 1,11 & 1,67 & 4,02 & 0,41 & 1 & 1 & 1 & 1 & 1 & 1 & 1,86 & 3,86 & 0,23 & 0,06 \\
\hline$f_{25}$ & 0,30 & 0,54 & 1 & 1 & 1 & 0,47 & 0,37 & 0,78 & 1 & 0,26 & 0,54 & 1 & 1 & 1 & 1 & 0,10 & 0,02 \\
\hline
\end{tabular}

Table 6 Fuzzy evaluation pair-wise comparison of the sub-criteria of main criterion $F_{3}$

\begin{tabular}{|c|c|c|c|c|c|c|c|c|c|c|c|c|c|c|c|c|c|}
\hline$F_{3}$ & \multicolumn{3}{|c|}{$f_{31}$} & \multicolumn{3}{|c|}{$f_{32}$} & \multicolumn{3}{|c|}{$f_{33}$} & \multicolumn{3}{|c|}{$f_{34}$} & \multicolumn{3}{|c|}{$f_{35}$} & \multicolumn{2}{|c|}{ Weight } \\
\hline & $l$ & $m$ & $u$ & $l$ & $m$ & $u$ & $l$ & $m$ & $u$ & $l$ & $m$ & $u$ & $l$ & $m$ & $u$ & Local & Global \\
\hline$f_{31}$ & 1 & 1 & 1 & 1 & 2,43 & 4,14 & 1 & 2,71 & 4,71 & 1,29 & 3,29 & 5,29 & 1,29 & 2,71 & 4,71 & 0,31 & 0,10 \\
\hline$f_{32}$ & 0,24 & 0,41 & 1 & 1 & 1 & 1 & 1 & 1,86 & 3,57 & 1 & 1,86 & 3,29 & 1 & 1,86 & 3,86 & 0,24 & 0,08 \\
\hline$f_{33}$ & 0,21 & 0,37 & 1 & 0,28 & 0,54 & 1 & 1 & 1 & 1 & 1 & 1 & 2,14 & 1 & 1,57 & 2,71 & 0,18 & 0,06 \\
\hline$f_{34}$ & 0,19 & 0,30 & 0,78 & 0,30 & 0,54 & 1 & 0,47 & 1 & 1 & 1 & 1 & 1 & 1 & 1,57 & 2,71 & 0,16 & 0,05 \\
\hline$f_{35}$ & 0,21 & 0,37 & 0,78 & 0,26 & 0,54 & 1 & 0,37 & 0,64 & 1 & 0,37 & 0,64 & 1 & 1 & 1 & 1 & 0,11 & 0,03 \\
\hline
\end{tabular}

Table 7 Fuzzy evaluation pair-wise comparison of the sub-criteria of main criterion $F_{4}$

\begin{tabular}{|c|c|c|c|c|c|c|c|c|c|c|c|c|c|c|}
\hline \multirow[t]{2}{*}{$F_{4}$} & \multicolumn{3}{|c|}{$f_{41}$} & \multicolumn{3}{|c|}{$f_{42}$} & \multicolumn{3}{|c|}{$f_{43}$} & \multicolumn{3}{|c|}{$f_{44}$} & \multicolumn{2}{|c|}{ Weight } \\
\hline & $l$ & $m$ & $u$ & $l$ & $m$ & $u$ & $l$ & $m$ & $u$ & $l$ & $m$ & $u$ & Local & Global \\
\hline$f_{41}$ & 1 & 1 & 1 & 1 & 2,43 & 3,86 & 1 & 2,71 & 4,71 & 1,86 & 3,86 & 5,86 & 0,37 & 0,11 \\
\hline$f_{42}$ & 0,26 & 0,41 & 1 & 1 & 1 & 1 & 1 & 1,57 & 3,00 & 1 & 2,14 & 3,86 & 0,27 & 0,08 \\
\hline$f_{43}$ & 0,21 & 0,37 & 1 & 0,33 & 0,64 & 1 & 1 & 1 & 1 & 1 & 2,71 & 4,71 & 0,25 & 0,07 \\
\hline$f_{44}$ & 0,17 & 0,26 & 0,54 & 0,26 & 0,47 & 1 & 0,21 & 0,37 & 1 & 1 & 1 & 1 & 0,11 & 0,03 \\
\hline
\end{tabular}
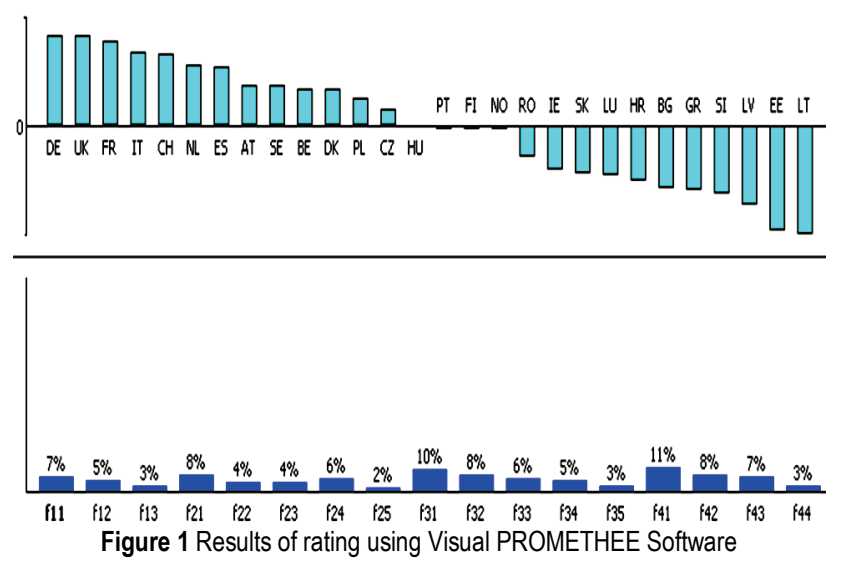

Fig. 1 presents the results obtained by means of the Visual PROMETEE Software, where the ranking and the weights of criteria are illustrated.

In Tab. 8 is presented the ranking and values of outranking flows by PROMETEE Method.

Table 8 Ranking, outranking flows by PROMETEE Method
\begin{tabular}{|c|c|c|c|c|c|c|c|c|c|}
\hline Rank & $\varphi$ & $\varphi^{+}$ & $\varphi^{-}$ & Rank & $\varphi$ & $\varphi^{+}$ & $\varphi^{-}$ \\
\hline 1 & DE & 0,64 & 0,74 & 0,10 & 15 & PT & $-0,02$ & 0,40 & 0,42 \\
\hline 2 & UK & 0,63 & 0,73 & 0,10 & 16 & FI & $-0,03$ & 0,39 & 0,42 \\
\hline 3 & FR & 0,60 & 0,72 & 0,12 & 17 & NO & $-0,03$ & 0,40 & 0,43 \\
\hline 4 & IT & 0,51 & 0,67 & 0,16 & 18 & RO & $-0,22$ & 0,30 & 0,52 \\
\hline 5 & CH & 0,51 & 0,67 & 0,16 & 19 & IE & $-0,31$ & 0,27 & 0,57 \\
\hline 6 & NL & 0,43 & 0,63 & 0,20 & 20 & SK & $-0,33$ & 0,25 & 0,58 \\
\hline 7 & ES & 0,41 & 0,61 & 0,21 & 21 & LU & $-0,35$ & 0,24 & 0,59 \\
\hline 8 & AT & 0,29 & 0,57 & 0,28 & 22 & HR & $-0,40$ & 0,22 & 0,61 \\
\hline 9 & SE & 0,29 & 0,56 & 0,27 & 23 & BG & $-0,45$ & 0,19 & 0,64 \\
\hline 10 & BE & 0,27 & 0,56 & 0,29 & 24 & GR & $-0,46$ & 0,19 & 0,64 \\
\hline 11 & DK & 0,26 & 0,55 & 0,29 & 25 & SI & $-0,49$ & 0,17 & 0,66 \\
\hline 12 & PL & 0,20 & 0,51 & 0,31 & 26 & LV & $-0,56$ & 0,14 & 0,70 \\
\hline 13 & CZ & 0,11 & 0,47 & 0,36 & 27 & EE & $-0,74$ & 0,05 & 0,79 \\
\hline 14 & HU & 0,00 & 0,42 & 0,42 & 28 & LT & $-0,77$ & 0,04 & 0,81 \\
\hline
\end{tabular}

The research indicates that the most highly developed railway passenger transport, when all factors are taken into account, is in Germany, Britain and France. In the next group of countries with developed railway passenger transport are Italy, Switzerland, Netherlands and Spain. From Tab. 8 it can be seen that these seven countries have $\varphi>0,4$.

These results are similar to the ranking made in $[1,2$, $3,14,24]$, which also place the above mentioned countries in the top positions, although the authors examined total rail passenger and freight transport.

A sensitivity analysis has been done to examine the sensitivity of results. The sub-criteria: infrastructure charges, euro/train.km (up to 3,46\%), the average number of passengers per train (up to $8,13 \%$ ), the passenger network usage intensity (up to $10,03 \%$ ) and the average distance travelled per resident, $\mathrm{km}$ (from 1,67\% to 14,68 $\%$ ) have small stability intervals. A great number of the criteria have wide intervals of stability (up to $100 \%$ ). It can be summarised that the sub-criteria of the second main group have a waste interval of stability. This is due to the already constructed railway networks in the European countries. Most of the sub-criteria of the third and fourth main groups, which indicate the travel and technological level, have small intervals of stability. This is due to the stochastic variation of passenger travel.

The Cluster Analysis has been applied to verify the results. Statistical Package for Social Science (SPSS) software has been used for carrying out the study with a cluster analysis. The dendrogram of the formed clusters and their respective elements are shown in Fig. 2. 


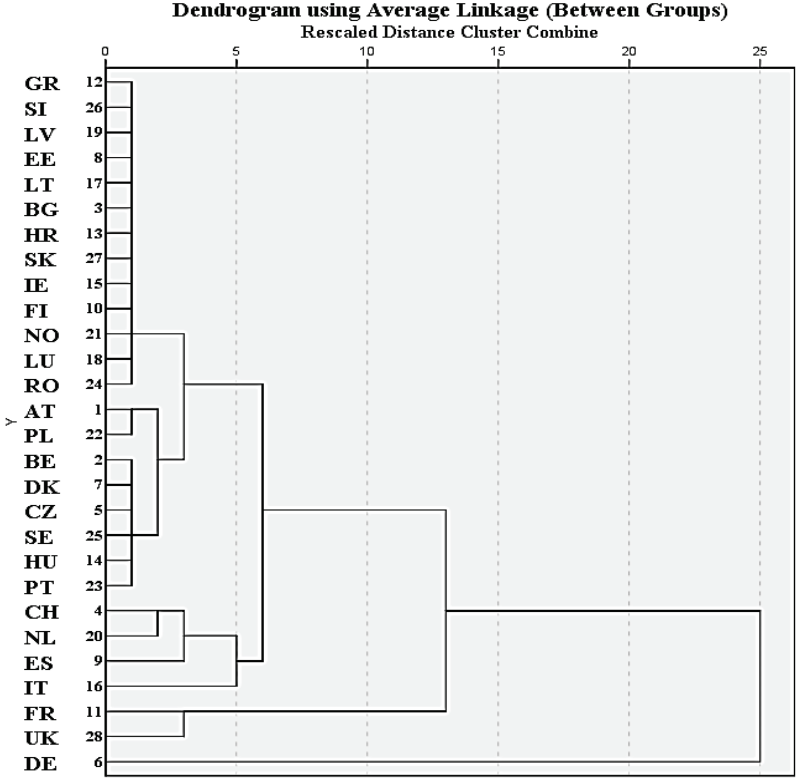

Figure 2 Dendrogram of clusterization (SPSS Software)

Tab. 9 shows the value of $F$ criterion for the examined sub-criteria. The theoretical value of $F$ criterion is defined by using standard tables and is $F_{\mathrm{T}}=2,49, k_{1}=$ $28-17=16, k_{2}=17-1=16$, level of risk $\alpha=0,05$.The results of $\mathrm{F}$ criterion show similar results of impact of sub-criteria with results given by FAHP method.

Table $9 F$ criterion for sub-criteria

\begin{tabular}{|c|c|c|c|c|c|c|c|c|}
\hline$f_{11}$ & $f_{12}$ & $f_{13}$ & $f_{21}$ & $f_{22}$ & $f_{23}$ & $f_{24}$ & $f_{25}$ & $f_{31}$ \\
\hline 99,8 & 0,2 & 1,2 & 20,5 & 3,4 & 0,4 & 3,2 & 11,4 & 192,3 \\
\hline$f_{32}$ & $f_{33}$ & $f_{34}$ & $f_{35}$ & $f_{41}$ & $f_{42}$ & $f_{43}$ & $f_{44}$ & \\
\hline 100,1 & 1,5 & 2,4 & 3,9 & 155,4 & 4,2 & 4,8 & 0,5 & \\
\hline
\end{tabular}

The results of $F$ criterion show that the greatest impacts on the classification have the following factors: number of passengers per year $\left(f_{31}\right)$, number of passenger train kilometers per year $\left(f_{41}\right)$, number of passengerkilometres $\left(f_{32}\right)$, gross domestic product $\left(f_{11}\right)$, billion euro/year, length of the railway network, $\mathrm{km}\left(f_{21}\right)$. From Tab. 4, Tab. 5, Tab. 6, Tab. 7 and Tab. 9 can be seen that the results of importance of sub-criteria expressed by global weights using the FAHP method and $F$ criterion using Cluster analysis are similar.

The results indicate that railway passengers systems of the considered European countries can be classified into four groups:

- 1 group: This cluster contains Germany.

- 2 group: This cluster contains 2 railway passengers systems -United Kingdom and France.

- 3 group: This cluster contains 4 countries - Italy, Spain, Netherlands and Switzerland.

- 4 group: This cluster contains 8 countries - Belgium, Denmark, Czech Republic, Sweden, Hungary, Portugal, Austria and Poland.

- 5 group: This cluster contains 13 countries - Romania, Luxemburg, Norway, Finland, Ireland, Slovakia, Croatia, Bulgaria, Lithuania, Estonia, Latvia, Slovenia and Greece.

From the dendrogram in Fig. 2 it can be seen that the first, second and third cluster have a large distance between them. The third and fourth cluster has a short distance between them, but they are a long distance from other clusters. This indicates that the clusters are precisely defined.

Although the Cluster analysis gives a grouping of countries, while using multicriteria analysis, a ranking is obtained. The research indicates the similar results with FAHP and PROMETEE methods.

\section{CONCLUSIONS}

This paper presents a combination of multicriteria model for rating railway passenger transport development. The factors for the classification have been defined. The main groups of criteria are social and economic factors, infrastructure factors, factors associated with travel and technological factors. The research defines 17 sub-criteria, which characterise the main criteria.

The results show that the factors associated with travel and technological factors have a great importance in ranking of the countries.

The study produces a classification of 28 countries of the European Union using the proposed combination multicriteria model. The conducted study showed that the most highly developed railway passenger transport, when all factors are taken into account, is in Germany, Britain and France.

It was found that the presented model of establishing the rating based on multicriteria methods gave similar results as the other method of classification, Cluster Analysis. Thus the obtained results have been verified. The research shows that the passenger railway transport in the European Union countries can be classified into 5 groups.

The classification could be used for European countries to compare the level of development of passenger rail transport, and can help railway companies in their analysis of the state of transportation and in decision-making, in considering the technology for the development of railway passenger transport and extending their services.

Further research will be based on the development of a model for investigation of all types of transport in the studied countries.

\section{REFERENCES}

[1] Report from the commission to the council and the European Parliament: Fourth Report to the Council and the European Parliament on monitoring development of the rail market. European Commission, Brussels, 2014. http://ec.europa.eu/transport/modes/rail/market/doc/swd.

[2] Fourth Annual Market Monitoring Report. IRG-Rail, 2016, http://www.irg-rail.eu/public-documents

[3] Statistique international des Chemins de Fer. UIC-Centre de Statistique, Paris, 2010.

[4] Arrigo, U. \& Di Foggia, G. (2014). Theoretical and viable charging models for railway infrastructure access. European survey management research and practice, 6(2), 5-24.

[5] Wetzel. H. (2008). European Railway Deregulation: The Influence of Regulatory and Environmental Conditions on Efficiency. Working Paper Series in Economics, 86. http://www.uni-lueneburg.de/fb2/vwl/papers/wp_86_ Upload.pdf. (05.11.2016) 
[6] Loizides, L. \& Tsionas, E. (2002). Productivity growth in European railways: a new approach. Transportation Research Part A, 36, 633-644. https://doi.org/10.1016/S0965-8564(01)00027-1

[7] Urdánoz, M. \& Vibes, C. (2013). Regulation and cost efficiency in the European railways industry. Journal of Productivity Analysis, 39, 217-230. https://doi.org/10.1007/s11123-012-0284-0.

[8] Coelli, T. \& Parelman, S. (2000). Technical Efficiency of European Railways: A Distance Function Approach. Applied Economics, 32(15), 1967-1976. https://doi.org/10.1080/00036840050155896

[9] Lan, L. \& Lin, E. (2006). Performance measurement for railway transport: stochastic distance functions with inefficiency and ineffectiveness effects. Journal of Transport, Economics and Policy, 40(3), 83-408.

[10] Cantos, P., Pastor, J., \& Serrano, L. (1999). Productivity, efficiency and technical change in the European railways: a non-parametric approach. Transportation, 26(4), 337-357. https://doi.org/10.1023/A:1005127513206

[11] Cantos, P., Pastor, M., \& Serrano, L. (2002). Cost and revenue inefficiencies in the European railways. International Journal of Transport Economics, 29(3), 279308.

[12] Kutlar, A., Kabasakal, A., \& Sarikaya, M. (2013). Determination of the efficiency of the world railway companies by method of DEA and comparison of their efficiency by Tobit analysis. Qual Quant, 47(4), 35753602. https://doi.org/10.1007/s11135-012-9741-0

[13] Merkert, R., Smith, A., \& Nash, C. (2010). Benchmarking of train operating firms: a transaction cost efficiency analysis. Transportation Planning and Technology 33(1), 35-53. https://doi.org/10.1080/0308106090342933

[14] Yu, M. (2008). Assessing the technical efficiency, service effectiveness, and technical effectiveness of the world's railways through NDEA analysis. Transportation Research Part A, 42, 1283-1294. https://doi.org/10,1016/j.tra.2008.03.014

[15] Justo, J. \& Suarez, C. (2003). Has the efficiency of European railway companies been improved? European Business Review, 15(4), 213-220. https://doi.org/10.1108/09555340310483794

[16] Fraszczyk, A., Lamb, T., \& Marinov, M. (2016). Are railways really that bad? An evaluation of rail systems, performance in Europe with a focus on passenger rail. Transportation Research Part A, 94, 573-591. https://doi.org/10.1016/j.tra.2016.10.018

[17] Stamos, I., Myrovali, G., \& Aifadopoulou, G. (2016). Formulation of a roadmap towards the enhancement of international rail passenger transport e The South East Europe example. Journal of Rail Transport Planning \& Management, 6, 89-98. https://doi.org/10.1016/j.jrtpm.2016.06.002

[18] Aifandopoulou, G., Stamos, I., Morfoulaki, M., \& Myrovali, G. (2015). Mapping the opportunities of rail transport; a data-driven methodology for capturing rail competitiveness at European level. Period. Polytech. Transp. Eng., 43(1), 48-54. https://doi.org/10.3311/PPtr.7739

[19] Cantos, P. \& Maudos, J. (2001). Regulation and efficiency: the case of European railways. Transportation Research Part A, 35, 459-472. https://doi.org/10.1016/S0965-8564(00)

[20] Arrigo. U. \& Di Foggia. G. (2013). Schemes and Levels of State Aid to Rail Industry in Europe: Evidences from a Cross-Country Comparison. European Journal of Business and Economics, 8(3), 14-20. https://doi.org/10.12955/ejbe.v8i3.410

[21] Wetzel, H. (2008). Productivity Growth in European Railways: Technological Progress, Efficiency Change and Scale Effects. Working Paper Series in Economics No. 101. http://www.uni-lueneburg.de/fb2/vwl/papers/wp 101 Upload.pdf (05.11.2016)

[22] Vesković, C., Raičević, V., Stojić, G., \& Milinković, S. (2012). A model to estimate the passenger rail liberalisation: The case of Serbia. International Journal for Traffic and Transport Engineering, 2(3), 202-220. https://doi.org/10.7708/ijtte.2012.2(3).04

[23] Jaržemskis, A.; Jaržemskis, V. (2014). The differences in efficiency measurement: the case of European railways. Transport and Telecommunication, 15(2), 151-163.

[24] Beria, P., Quinet, E., de Rus, G., \& Schulz, C. (2012). A comparison of rail liberalisation levels across four European countries. Research in Transportation Economics, 36(1), 110-120. https://doi.org/10.1016/j.retrec.2012.03.014

[25] Chang, D. (1996). Applications of the Extent Analysis Method on Fuzzy AHP. European Journal of Operational Research, 95(3), 649-655. https://doi.org/10.1016/0377-2217(95)00300-2

[26] Moazeni, K. (2014). Assessment of urban welfare to achieve sustainable urban development using an integrated Fuzzy AHP-VIKOR with a case study. Tehnički vjesnik, 21(6), 1281-1288.

[27] Moradi, A., Etebarian, A., Shirvani, A., \& Soltani, I. (2014). Development of a fuzzy model for Iranian marine casualties management. Journal of Fuzzy Set Valued Analysis, Volume 2014, Article ID jfsva-00186, 1-17. https://doi.org/10.5899/2014/jfsva-00186

[28] Özdağoğlu, A. \& Güler, E. (2016). E-service quality of Internet based banking using combined fuzzy AHP and fuzzy TOPSIS. Tehnički vjesnik, 23(4), 1109-1116. https://doi.org/10.17559/TV-20140801181553

[29] Kwong, C. K. \& Bai, H. (2003). Determining the Importance Weights for the Customer Requirements in QFD Using a Fuzzy AHP with an Extent Analysis Approach. IIE Transactions, 35, 616-626. https://doi.org/10.1080/07408170304355.

[30] Saaty, T. (2000). Fundamentals of Decision Making and Priority Theory with the Analytic Hierarchy Process, 1-st ed. RWS Publications.

[31] Srinivasa, R. \& Kumar, D. (2014). Multicriterion Analysis in Engineering and Management. PHL Learning Private Limited, Delhi.

[32] Tan, P., Steinbach, M., \& Kumar, U. (2006). Introduction to Data mining. Minnesota: University of Minnesota.

[33] Kil, S., Lee, D., Kim, J., Li, M., \& Newman, G. (2016). Utilizing the Analytic Hierarchy Process to Establish Weighted Values for Evaluating the Stability of Slope Revegetation based on Hydroseeding Applications in South Korea. Sustainability $8(58), 1-17$ https://doi.org/10.3390/su8010058.

[34] Lee, C., Wan, J., Shi, W., \& Li, K. (2014). A cross-country study of competitiveness of the shipping industry. Transport Policy, 35, 366-376. https://doi.org/10.1016/j.tranpol.2014.04.010.

\section{Contact information}

Svetla STOILOVA, Assoc. Prof. PhD

Technical University-Sofia, Faculty of Transport,

1000 Sofia, $8 \mathrm{Kl}$, Ohridski Blvd, Bulgaria

E-mail: stoilova@tu-sofia.bg 